\title{
Modulating Structure and Properties of Glutinous Rice Flour and Its Dumpling Products by Annealing
}

\author{
Chengming Shi ${ }^{1,2,3}$, Song Zhu ${ }^{1}$, Guangqin Ding ${ }^{1,2}$, Chaodong Du ${ }^{1,2}$, Dejian Huang ${ }^{4}$ and Yue $\mathrm{Li}^{1,2, *}$ \\ 1 State Key Laboratory of Food Science and Technology, Jiangnan University, Wuxi 214122, China; \\ shichengming2020@163.com (C.S.); zhusong@jiangnan.edu.cn (S.Z.); ap15190253301@163.com (G.D.); \\ 18801515252@163.com (C.D.) \\ 2 School of Food Science and Technology, Jiangnan University, Wuxi 214122, China \\ 3 International Joint Laboratory on Food Safety, Jiangnan University, Wuxi 214122, China \\ 4 Department of Food Science and Technology, National University of Singapore, Singapore 117542, Singapore; \\ fsthdj@nus.edu.sg \\ * Correspondence: liyue@jiangnan.edu.cn; Tel.: +86-13915335603
}

Citation: Shi, C.; Zhu, S.; Ding, G.; Du, C.; Huang, D.; Li, Y. Modulating Structure and Properties of Glutinous Rice Flour and Its Dumpling Products by Annealing. Processes 2021, 9, 2248. https://doi.org/10.3390/pr9122248

Academic Editor: Jurislav Babić

Received: 8 November 2021

Accepted: 10 December 2021

Published: 14 December 2021

Publisher's Note: MDPI stays neutral with regard to jurisdictional claims in published maps and institutional affiliations.

Copyright: (c) 2021 by the authors. Licensee MDPI, Basel, Switzerland. This article is an open access article distributed under the terms and conditions of the Creative Commons Attribution (CC BY) license (https:/ / creativecommons.org/licenses/by/ $4.0 /)$.

\begin{abstract}
In this study, annealed glutinous rice flour treated under different conditions (ANN1, ANN2 and ANN3) were prepared. The structure as well as physicochemical characteristics of the flour and its dumpling products were investigated. The crystallinity of the annealed flour samples increased, while the hydration ability decreased. The content of bound water raised, and immobilized water as well as the freezing enthalpy value decreased for the fast-frozen dumplings made from annealed flour samples. It showed that annealed treatment could reduce the formation of large ice crystals, thus decrease the cracking of fast-frozen dumplings. The freezing enthalpy value of annealed dumplings decreased which was conducive to protect the structure and quality of products. The boiled dumplings made of annealed flour had better eating quality as demonstrated by the increase in the transmittance of the soup. It indicated that moderate annealed glutinous rice flour ANN2 had optimal physicochemical properties to make high quality dumplings. This study would pave the way for further study of the annealing glutinous rice flour and provide theoretical guidance for the application of annealing treatment in starchy food product.
\end{abstract}

Keywords: glutinous rice flour; starch; annealing; dumpling; physicochemical characteristics

\section{Introduction}

Glutinous rice, is considered to be the great material for thickening soups, staple foods, and desserts due to its characteristic stickiness and opaque appearance $[1,2]$. Glutinous dumplings as a kind of popular traditional foods, is the specific food at the Lantern Festival in China [3,4]. The dumplings are usually made from glutinous rice flour, which are sticky and soft with round shape. After preparation, the dumplings need to be placed in the refrigerator at $-20{ }^{\circ} \mathrm{C}$ and be frozen for more than 6 months. The quality of fastfrozen dumplings is affected by many factors such as raw material quality, production process, storage method and so on. Unfavorable factors could cause problems such as freezing cracks, poor appearance, and poor taste of fast-frozen dumplings [5]. The quality of the product could be greatly enhanced by improving the physicochemical properties of glutinous rice flour itself, such as hydration ability, rheological properties, thermal properties and so on [6].

Annealing treatment is a kind of hydrothermal treatments, and often used to modify physicochemical properties of starch, and its chemical safety, low-cost and environmentfriendliness attracted much attention $[7,8]$. Annealing is a method that treat starch in excess water $(>60 \%)$ at temperatures below gelatinization but above the glass transition temperature, and it influences hydration ability, thermal properties, swelling power, solubility of starch [9]. Tsutsui et al. [10] prepared annealed sample at $62{ }^{\circ} \mathrm{C}$ for $15 \mathrm{~min}$, and observed 
that the annealing tended to prevent starch sample from shear thinning. Wang et al. [11] reported that annealing treatment changed the gel texture of rice starch and the qualities of the rice starch noodles were improved. Ghani et al. [12] found an increased gelatinization temperature and enthalpy of sago starch after annealing treatment.

Studies on the annealing effects on properties of glutinous rice flour and its products are relatively limited. In order to improve the quality of fast-frozen dumplings, annealing treatment on the glutinous rice flour is considered as a desirable way, because it could improve the fast-frozen rate and the transmittance of the food [10]. In our previous study, it was found that annealing treatment decreased digestibility of glutinous rice four, and improved the sensory properties of fast-frozen dumplings [3].

In this study, investigation was carried out to evaluate the effects of annealing treatment on the structure and physicochemical characteristics of glutinous rice flour and its fast-frozen rice dumpling products. Average molecular weight of glutinous rice starch, crystalline structure, hydration, and thixotropic properties of glutinous rice flour as well as the water distribution, thermal property and soup transmittance of the fast-frozen rice dumpling products were evaluated. This work would provide theoretical guidance for the application of annealing treatment in starchy food product.

\section{Materials and Methods}

\subsection{Materials}

The glutinous rice (Nongken Rice Co., Ltd., Nanjing, China) was soaked for $4 \mathrm{~h}$, then drained and ground. The sample was placed in an oven at $50{ }^{\circ} \mathrm{C}$ for $6 \mathrm{~h}$. After drying, the samples passed through a $120 \mu \mathrm{m}$ mesh sieve and were stored at $4{ }^{\circ} \mathrm{C}$.

\subsection{Annealing Treatment of Glutinous Rice Flour}

Annealed glutinous rice flour was prepared in various condition including different moisture content, temperature and time following our previous study [3]. Our preliminary studies found that glutinous rice flour annealed with $55 \%$ moisture, $50{ }^{\circ} \mathrm{C}, 4 \mathrm{~h}$ (ANN1); $55 \%$ moisture, $50^{\circ} \mathrm{C}, 6 \mathrm{~h}$ (ANN2) and $50 \%$ moisture, $55^{\circ} \mathrm{C}, 6 \mathrm{~h}$ (ANN3) showed relatively good freeze-thaw stability. Thus, these three samples were prepared for further analysis.

\subsection{The Extraction of Glutinous Rice Starch}

Glutinous rice flour and $0.2 \% \mathrm{NaOH}$ solution were blended in a ratio of $1: 5$ and stirred for $4 \mathrm{~h}$ at $37^{\circ} \mathrm{C}$. Then the sample was centrifuged at room temperature $(10,000 \times g, 10 \mathrm{~min})$, and the precipitation was washed many times until the $\mathrm{pH}$ value was neutral. The sample was dried in an oven at $50{ }^{\circ} \mathrm{C}$. After drying, the glutinous rice starch was obtained by grinding and sieving through 120 mesh.

\subsection{Determination of Average Molecular Weight of Glutinous Rice Starch}

The average molecular weight $\left(\mathrm{M}_{\mathrm{W}}\right)$ and the radius of gyration $\left(\mathrm{R}_{\mathrm{z}}\right)$ of glutinous rice starch samples were analyzed using high-performance size exclusion chromatography coupled with multi-angle laser light scattering and refractive index detectors (HPSECMALLS-RI, Shimadzu, Kyoto, Japan) following the method by Chang et al. with some modifications [13]. The samples (10 mg) were thoroughly dissolved in $10 \mathrm{~mL}$ dimethyl sulfoxide (DMSO) with $50 \mathrm{mmol} / \mathrm{L} \mathrm{NaNO}_{3}$ in a $90^{\circ} \mathrm{C}$ water bath for $30 \mathrm{~min}$ with stirring for $24 \mathrm{~h}$. The starch solution was centrifuged $(10,000 \times g, 3 \mathrm{~min})$ and the supernatant was diluted, filtered $(0.45 \mu \mathrm{m}$ water phase nylon syringe filter) and injected into HPSEC system.

The HPSEC system consisted of an HP 1050 series pump and an autoinjector injector (Hewlett Packard, Valley Forge, PA, USA) fitted with a $100 \mu \mathrm{L}$ injection loop. The system also employed a multi-angle laser light scattering detector (MALLS) (Dawn DSP-F, Wyatt Tech., Santa Barbara, CA, USA) and a differential refractometer detector (RI) (model ERC7512, ERMA Inc., Tokyo, Japan). The chromatographic column consisted of Styragel HMW 6E DMF and HMW $2 \mathrm{MF}$ in tandem for separation of samples. The temperature of the 
columns was maintained $45^{\circ} \mathrm{C}$. The samples were eluted at a flow rate of $0.6 \mathrm{~mL} / \mathrm{min}$ with $50 \mathrm{mmol} / \mathrm{L} \mathrm{NaNO}_{3}$ in DMSO as a mobile phase.

The data were analyzed by the Astra software (version 5.3.4, Wyatt Technology), and the heavy mean molecular weight $(\mathrm{Mw})$ and mean radius of rotation $(\mathrm{Rz})$ of starch were calculated by using the second order Berry model.

\subsection{Determination of Crystallinity}

X-ray diffraction (XRD) patterns of glutinous rice flour were performed with an X-ray diffractometer (Bruker D2, AXS Co., Ltd., Karlsruhe, Germany). The voltage was 40 kV, the current was $40 \mathrm{~mA}$, diffractograms were obtained by scanning from $5^{\circ}$ to $60^{\circ}$ at a speed of $4^{\circ} / \mathrm{s}$. The crystallinity was calculated by Software Jade 9.0.

\subsection{Determination of Hydration Ability}

The water solubility (WS), water absorption index (WAI) and swelling power (SP) of the samples were measured following the method by Abebe et al. [14] with slight modifications. The sample of glutinous rice flour $(0.5 \mathrm{~g})$ was dispersed in $30 \mathrm{~mL}$ of distilled water and placed in pre-weighed $50 \mathrm{~mL}$ centrifuged tube $\left(\mathrm{m}_{0}\right)$ with continuously stirring for $30 \mathrm{~min}$ at room temperature. Then the sample was centrifuged at $3000 \times g$ for $20 \mathrm{~min}$ and the supernatant $\left(\mathrm{m}_{1}\right)$ was dried in the oven at $105^{\circ} \mathrm{C}$, then weighed. The residual precipitation $\left(\mathrm{m}_{2}\right)$ was weighed. WS, WAI and SP were calculated using the following equations:

$$
\begin{gathered}
\text { WS }(\%)=\mathrm{m}_{1} / \mathrm{m} \times 100 \\
\text { WAI }=\left(\mathrm{m}_{2}-\mathrm{m}_{0}\right) / \mathrm{m} \\
\mathrm{SP}=\left(\mathrm{m}_{2}-\mathrm{m}_{0}\right) /[\mathrm{m} \times(1-\mathrm{WS})]
\end{gathered}
$$

WS is the water solubility (\%), WAI is the water absorption index, and SP is the swelling power. $\mathrm{m}_{0}$ is the weight of centrifuge tube $(\mathrm{g}), \mathrm{m}_{1}$ is the weight of supernatant after drying $(\mathrm{g}), \mathrm{m}_{2}$ is the weight of centrifuge tube and precipitate $(\mathrm{g}), \mathrm{m}$ is the weight (dry base) of the sample (g).

\subsection{Determination of Gel Consistency}

Gel consistency of rice flour was measured following the method by Tran et al. [15] with slight modifications. Glutinous rice flour samples (100 $\pm 1 \mathrm{mg}, 12 \%$ moisture) were added into $0.2 \mathrm{~mL}$ of $0.025 \%$ bromothymol blue ethanol solution and placed in tubes with constant stirring, and then $2.0 \mathrm{~mL}$ of $0.2 \mathrm{~mol} / \mathrm{L} \mathrm{KOH}$ was added into it. The tubes were incubated in a boiling water bath for $8 \mathrm{~min}$ then put at room temperature for $5 \mathrm{~min}$. At the last, the tubes were put in an ice-water bath about $0^{\circ} \mathrm{C}$ for $15 \mathrm{~min}$. The tubes were placed horizontally on a ruled scale workbench and the flow length of the gels in the test tubes were measured after setting for $1 \mathrm{~h}$ at $25 \pm 2{ }^{\circ} \mathrm{C}$.

\subsection{Determination of Thixotropic Properties}

The thixotropic properties of gelatinized glutinous rice flour $(12 \% w / w)$ were conducted using a DHR-3 rheometer (TA Instrument, New Castle, DE, USA) in the Flow model with a $40 \mathrm{~mm}$ diameter plate. The parameters were as follows: the shear rate was increased from 0.01 to $200 \mathrm{~s}^{-1}$ at $50{ }^{\circ} \mathrm{C}$ and then decreased from 200 to $0.01 \mathrm{~s}^{-1}$ within $2 \mathrm{~min}$. The gap was set at $1 \mathrm{~mm}$. To ensure that the sample would not dry out, dimethicone was added to the dough surface, and a thermal jacket was used for insulated.

\subsection{Methods of Making Fresh and Fast-Frozen Glutinous Dumplings}

The fast-frozen dumplings were prepared following the method by Li et al. [3]. The dough was prepared by mixing the weighed flour and 95\% weight of water, and kneading, then kept it in a rest for $20 \mathrm{~min}$. The dough $(10 \mathrm{~g})$ was made round, and the fresh glutinous dumplings were obtained. Then the fresh dumplings were frozen at $-30{ }^{\circ} \mathrm{C}$ for $30 \mathrm{~min}$. The fast-frozen dumplings were obtained and stored at $-18{ }^{\circ} \mathrm{C}$. 


\subsection{Determination of Water Distribution in Fresh Glutinous Dumplings}

Water distribution in fresh glutinous dumpling was measured using low field NMR (LF-NMR) imaging analyzer (Shanghai Niumag Co., Ltd., Shanghai, China). The spinspin relaxation time $\left(\mathrm{T}_{2}\right)$ was measured using CPMG sequence (carr-purcell-meiboom-gill sequence). The parameters followed as: magnetic field strength was $0.5 \mathrm{~T}$, the temperature was $32{ }^{\circ} \mathrm{C}$, sampling frequency was $200 \mathrm{kHz}$, repeat sampling latency was $100 \mathrm{~ms}$, echo time was $0.2 \mathrm{~ms}$, echo number was 1000 , accumulated number was 4 . After the scan, the water distribution was obtained from cumulative integration.

\subsection{Determination of Freezing Point of Fresh Glutinous Dumplings}

The freezing point of fresh glutinous dumpling was measured with differential scanning calorimetry (DSC) (DSC 8500, PERKIN ELMER, Wellesley, MA, USA). The temperature of dumplings was decreased from $20^{\circ} \mathrm{C}$ to $-20^{\circ} \mathrm{C}$ at the rate of $5^{\circ} \mathrm{C} / \mathrm{min}$. Then the sample temperature was increased from $-20^{\circ} \mathrm{C}$ to $20^{\circ} \mathrm{C}$ at the rising rate of $5^{\circ} \mathrm{C} / \mathrm{min}$. The results obtained by this analysis comprised onset freezing $\left(\mathrm{T}_{\mathrm{fo}}\right)$, peak freezing $\left(\mathrm{T}_{\mathrm{fp}}\right)$ and conclusion freezing temperature $\left(\mathrm{T}_{\mathrm{fc}}\right)$.

\subsection{Determination of the Transmittance of Soup of Fast-Frozen Dumpling after Cooking}

Five dumplings passed accelerated experiment as a group were put into $500 \mathrm{~mL}$ distilled water and heated to boiling, covered the lid and kept the boiling for $5 \mathrm{~min}$ in $1200 \mathrm{~W}$, followed open the lid for $2 \mathrm{~min}$ in $800 \mathrm{~W}$, then removed the dumplings from the pan and kept the soup cool for $20 \mathrm{~min}$ to make up to $500 \mathrm{~mL}$. The light transmittance of the soup was measured at the wavelength of $650 \mathrm{~nm}$ using distilled water as a blank reference.

\subsection{Statistical Methods}

Results are shown as mean value and average standard deviation of at least triplicate measurements. Statistical analyses were carried out using the software SPSS 19.0 (SPSS, Inc., Chicago, IL, USA) and Origin 9.0 (Origin-Lab, Inc., Northampton, MA, USA) for Windows. The analysis of variance (ANOVA) and Tukey's test were used to analyze the significance difference among samples, and the level of confidence was $95 \%(p<0.05)$.

\section{Results and Discussion}

\subsection{Average Molecular Weight of Glutinous Rice Starch}

HPSEC-MALLS-RI is a widely used method for determining the molecular weight distribution of macromolecules. It is possible to observe the light intensity in all directions when a beam of light irradiates on a starch molecule, and the intensity is related with the shape, size and intermolecular interaction of the starch molecules in the solution $[16,17]$. As shown in Table $1, \mathrm{M}_{\mathrm{w}}$ of the native glutinous starch was $5.985 \times 10^{8}$, and the radius of gyration was $84.6 \mathrm{~nm}$. After annealing, the $\mathrm{M}_{\mathrm{W}}$ decreased, and the result obtained in our study was consistent with that reported by Zeng et al. [18]. It was because of the starch molecules degradation and rearrangement. The $M_{w}$ of sample ANN3 had the most significant change due to the strong treatment. $\alpha-1,6$ branched links crossing point in the non-crystalline region was destroyed easily and the molecular structure was damaged, leading to the decrease of molecular weight. It was reported that $R_{z}$ increased with the proportion of long branch-chains of amylopectin of the waxy rice starch increased [19]. After annealing, $\mathrm{R}_{\mathrm{z}}$ of the ANN1, ANN2 and ANN3 decreased from $84.6 \mathrm{~nm}$ to $79.2 \mathrm{~nm}$, $80.8 \mathrm{~nm}$ and $84 \mathrm{~nm}$, respectively. It was possible that the proportion of branch-chains of amylopectin of the samples changed during annealing.

\subsection{Crystalline Structure of Glutinous Rice Flour}

The native and annealed glutinous rice flour displayed strong characteristic diffraction single peaks at $15^{\circ}, 23.5^{\circ}$ and dual peaks at $17-18^{\circ}$ (Figure 1 ), indicating the samples were A-type patterns, and annealing treatment did not change the type of glutinous rice flour. However, the crystallinity increased slightly for ANN1 and ANN2, from 20.86 to 20.90 
and 22.63 respectively. The result was consistent with Wang et al. [20] who reported that annealing treatment did not alter the XRD patterns of pea starch granules, but slightly increased the relative crystallinity of pea starch granules. The starch granules were partially rearranged, the structure was more orderly, and spiral structure arrangement was closer during annealing treatment. In addition, crystallite perfection and size increased, the new crystallites were formed or the ordering of amylose-lipid complex was enhanced [21]. However, the crystallinity of sample ANN3 decreased slightly, because of the strong treatment, which may damage some crystalline area of starch granules.

Table 1. Average molecular weight $(\mathrm{Mw})$ and radius of rotation $(\mathrm{Rz})$ of native and annealed glutinous rice flour.

\begin{tabular}{ccc}
\hline Samples & $\mathbf{M}_{\mathbf{w}}\left(\times \mathbf{1 0 ^ { \mathbf { 8 } } )}\right.$ & $\mathbf{R}_{\mathbf{z}}(\mathbf{n m})$ \\
\hline Native & $5.985 \pm 0.023^{\mathrm{a}}$ & $84.6 \pm 0.3^{\mathrm{a}}$ \\
ANN1 & $2.709 \pm 0.044^{\mathrm{b}}$ & $79.2 \pm 0.7^{\mathrm{b}}$ \\
ANN2 & $2.685 \pm 0.033^{\mathrm{b}}$ & $80.8 \pm 0.1^{\mathrm{b}}$ \\
ANN3 & $1.873 \pm 0.012^{\mathrm{c}}$ & $84.0 \pm 1.6^{\mathrm{a}}$ \\
\hline
\end{tabular}

Note: Abbreviations: ANN1, $55 \%$ moisture, $50{ }^{\circ} \mathrm{C}, 4 \mathrm{~h}$; ANN2, $55 \%$ moisture, $50{ }^{\circ} \mathrm{C}, 6 \mathrm{~h}$; ANN3, $50 \%$ moisture, $55^{\circ} \mathrm{C}$, $6 \mathrm{~h} . \mathrm{M}_{\mathrm{W}}$, the average molecular weight; $\mathrm{R}_{\mathrm{z}}$, the radius of gyration. Results are expressed as mean \pm standard deviation. The letters $\mathrm{a}, \mathrm{b}$, and $\mathrm{c}$ indicated significant differences $(p<0.05)$ among the groups.

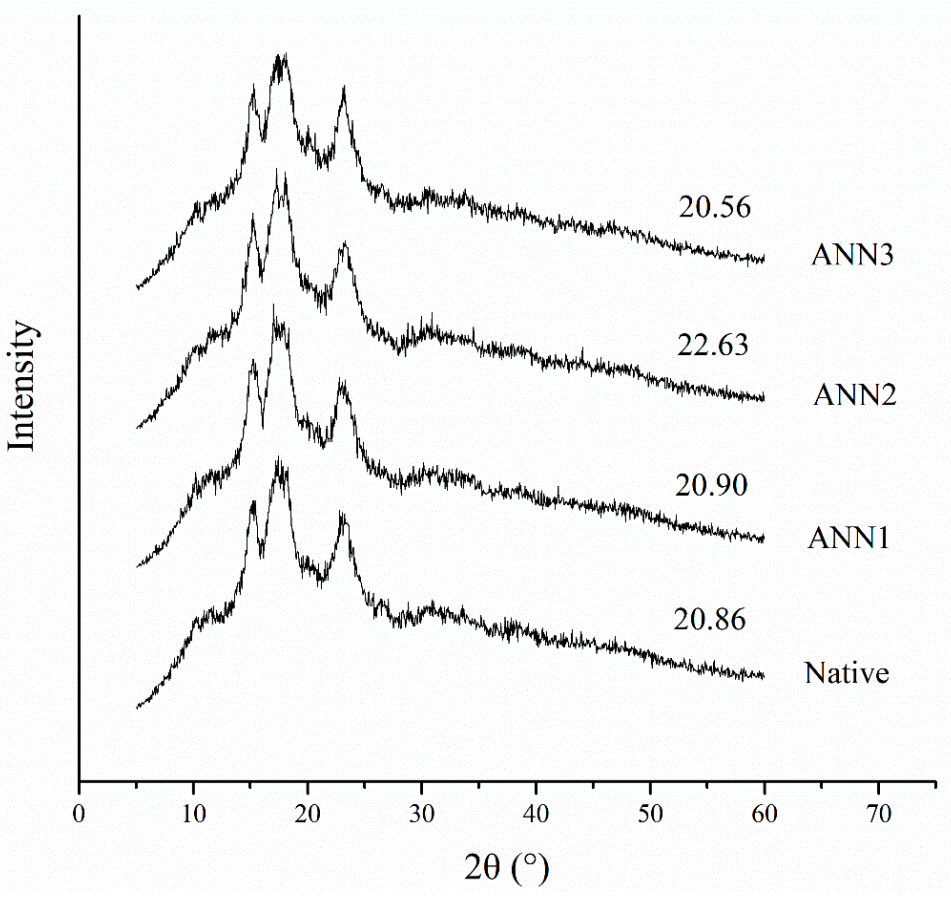

Figure 1. X-ray diffraction patters of native and annealed glutinous rice flour. ANN1, 55\% moisture, $50{ }^{\circ} \mathrm{C}, 4 \mathrm{~h}$; ANN2, 55\% moisture, $50{ }^{\circ} \mathrm{C}, 6 \mathrm{~h}$; ANN3, $50 \%$ moisture, $55^{\circ} \mathrm{C}, 6 \mathrm{~h}$.

\subsection{Hydration Ability of Glutinous Rice Flour}

The WS, WAI and SP are the parameters of the hydration ability of the samples, which are influenced by the interaction between amylose and amylopectin chains [11,22,23]. The WS was used to represent the degree of glutinous rice flour dispersion. SP was used to evaluate the ability of glutinous rice flour to swell freely during heating in water [1]. The hydration ability of native and annealed glutinous rice flour is shown in Figure 2. The WS, WSI and SP of glutinous rice flour samples after annealing (ANN1 and ANN2) were lower as compared to native glutinous rice flour. The result was consistent with Wang et al. [11], who reported that the swelling power and solubility of rice starch decreased significantly after annealing. Low hydration or solubility of glutinous rice flour is important to make high quality glutinous rice dumplings. The annealing treatment of glutinous rice 
flour could lead to produce the new crystallization in the amorphous region with the interaction of heat and moisture. Crystal integrity and the ordered structure resulted in opening and melting of the double helix structure were difficult during the swelling process $[24,25]$. Meanwhile, there was lipid in the glutinous rice flour, which was beneficial for the formation of starch-lipid complex during heat treatment, that limited the hydration of the amorphous domains of starch [26]. In addition, it was possible that a part of the branched chain structure was broken, which led to the decrease of its hydration ability. However, the WS, WSI and SP of ANN3 increased significantly (Figure 2). It was because of the strong treatment damaged some starch granules as well as the interaction of hydrogen bonds between starch amylose and amylopectin molecules, resulting in the increase of hydration ability.

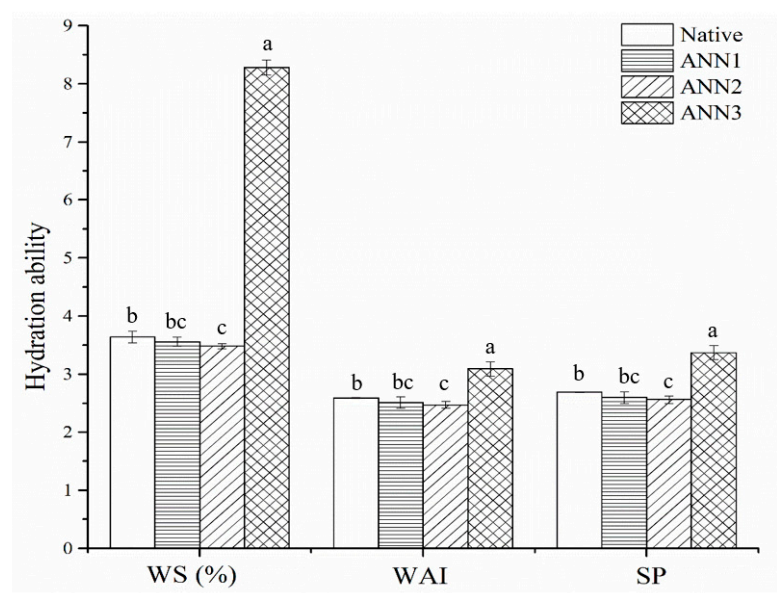

Figure 2. Water solubility (WS), water absorption index (WAI) and swelling power (SP) of native and annealed glutinous rice flour. ANN1, 55\% moisture, $50{ }^{\circ} \mathrm{C}, 4 \mathrm{~h}$; ANN2, $55 \%$ moisture, $50{ }^{\circ} \mathrm{C}, 6 \mathrm{~h}$; ANN $3,50 \%$ moisture, $55^{\circ} \mathrm{C}, 6 \mathrm{~h}$. Results are expressed as mean \pm standard deviation. The letters $\mathrm{a}, \mathrm{b}$, and $\mathrm{c}$ above the bars indicated significant differences $(p<0.05)$ among the groups.

\subsection{Gel Consistency and Thixotropic Properties of Glutinous Rice Flour}

Gel consistency, reflecting the softness and ductility of the gel, is an important index in evaluating the gel property of pasted glutinous rice flour. Gel consistency could be classified into different types based on the length of the gel: the length of gel $<40 \mathrm{~mm}$, $41-60 \mathrm{~mm}$ and $>61 \mathrm{~mm}$ represented hard gel, medium gel, and soft gel, respectively. The food made of soft gel was soft and palatable, and it could remain soft even after cooling. However, the food made of hard gel was stiff, dry and easy to crack [3]. As shown in Figure 3, the gel consistency of all the samples was relatively large, which indicated that the samples were soft gel. Gel consistency of the samples after annealing treatment decreased slightly compared with the native sample. While the length of all the samples was around $125 \mathrm{~mm}$, which had no effect on the taste quality of glutinous rice flour. Thus, all the annealed samples were suitable for making dumpling.

Thixotropy is the process that the liquid inner friction is reduced on shear after the destruction of the inner structure [27]. The most common method to determine thixotropy of the pastes is the test of the hysteresis loop [28,29]. As shown in Figure 4a, native and annealed gelatinized glutinous rice flour samples could form a thixotropic ring, and the areas of thixotropic ring of different samples were shown in Figure 4b. Compared with the native glutinous rice flour, the area of thixotropic ring of ANN2 was the largest, indicating that it had the strongest thixotropic property. The area of thixotropic ring of the sample ANN1 was slightly reduced compared with ANN2. However, the thixotropic property of the sample ANN3 reduced dramatically as compared with native sample. It confirmed that the annealing treatment conditions had a significant impact on the rheological property of glutinous rice flour [10]. The thixotropic property of sample ANN3 decreased, because the network structure of the pasted starch was damaged under the strong treatment condition. 
However, the gel systems formed by sample ANN1 and ANN2 were more stable, and more energy was required to destroy the network.

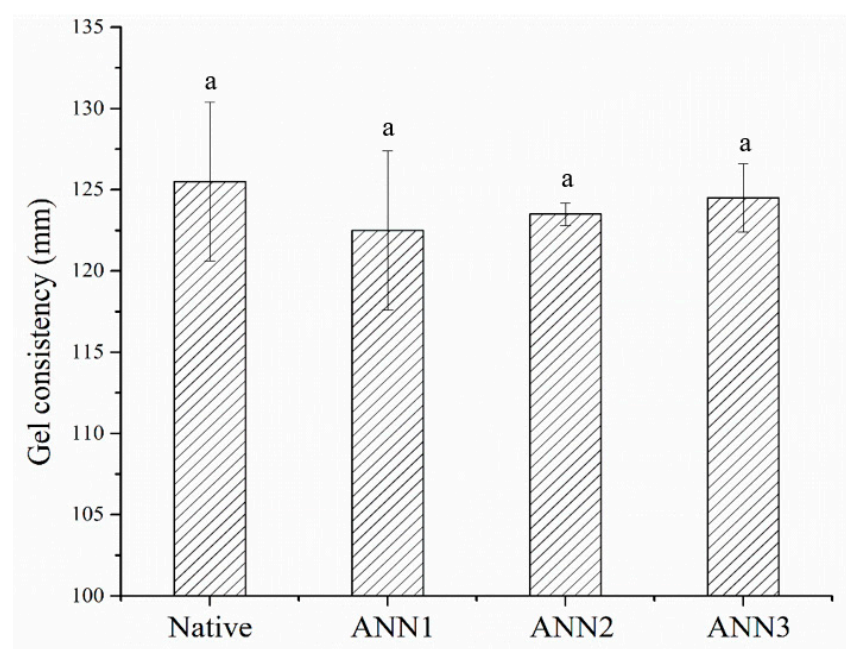

Figure 3. Gel consistency of native and annealed glutinous rice flour. ANN1, 55\% moisture, $50{ }^{\circ} \mathrm{C}$, $4 \mathrm{~h}$; ANN2, 55\% moisture, $50{ }^{\circ} \mathrm{C}, 6 \mathrm{~h}$; ANN3, 50\% moisture, $55{ }^{\circ} \mathrm{C}, 6 \mathrm{~h}$. Results are expressed as mean \pm standard deviation. The same letters above the bars indicated no significant differences among the groups $(p>0.05)$.
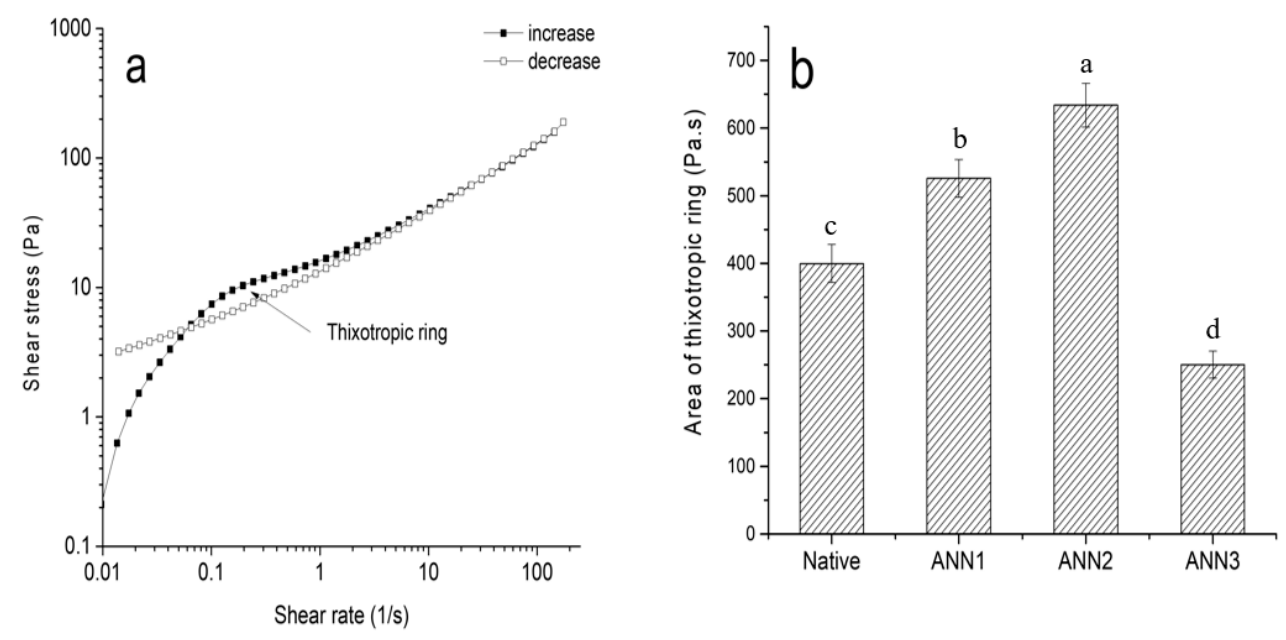

Figure 4. Rheological properties of native and annealed glutinous rice flour: (a) thixotropic ring; (b) the area of thixotropic ring. ANN1, 55\% moisture, $50{ }^{\circ} \mathrm{C}, 4 \mathrm{~h}$; ANN2, 55\% moisture, $50{ }^{\circ} \mathrm{C}, 6 \mathrm{~h}$; ANN3, 50\% moisture, $55{ }^{\circ} \mathrm{C}, 6 \mathrm{~h}$. Results are expressed as mean \pm standard deviation. The letters $\mathrm{a}, \mathrm{b}, \mathrm{c}$ and $\mathrm{d}$ above the bars indicated significant differences $(p<0.05)$ among the groups.

\subsection{Freezing Point of Dumplings Made from Glutinous Rice Flour}

The freezing point of glutinous rice fast-frozen dumplings was determined by DSC. The water of fast-frozen dumplings would freeze into solid ice and form an exothermal peak on the curve during the cooling process, and the $T_{f o}, T_{f p}$ and $T_{f c}$ was obtained from the curve. Table 2 showed that the fast-frozen dumplings made from annealed glutinous rice flour started freezing at a lower temperature, but the temperature range was narrowed, indicating that the dumpling would freeze quickly, which facilitated the formation of fine ice crystals. The freezing enthalpy $\left(\triangle \mathrm{H}_{\mathrm{f}}\right)$ value of fast-frozen dumplings made from annealed glutinous rice flour was lower, which was conducive to reduce energy consumption in the process of industrial production. Meanwhile, the decrease of freezing point could inhibit the recrystallization of ice crystals, and reduce the formation of large ice 
crystals, which was conducive to protect the structure and quality of products and reduce the freezing cracking rate of fast-frozen dumplings.

Table 2. Freezing point of fast-fresh glutinous dumplings made from native and annealed glutinous rice flour.

\begin{tabular}{lccccc}
\hline Samples & $\mathbf{T}_{\text {fo }}\left({ }^{\circ} \mathbf{C}\right)$ & $\mathbf{T}_{\text {fp }}\left({ }^{\circ} \mathbf{C}\right)$ & $\mathbf{T}_{\mathbf{f c}}\left({ }^{\circ} \mathbf{C}\right)$ & $\mathbf{T}_{\text {fc }}-\mathbf{T}_{\text {fo }}\left({ }^{\circ} \mathbf{C}\right)$ & $\triangle \mathbf{H}_{\mathbf{f}}(\mathbf{J} / \mathbf{g})$ \\
\hline Native & $-8.90 \pm 0.01^{\mathrm{a}}$ & $-8.96 \pm 0.00^{\mathrm{a}}$ & $-10.03 \pm 0.01^{\mathrm{a}}$ & $1.13 \pm 0.02^{\mathrm{a}}$ & $-94.54 \pm 0.02^{\mathrm{b}}$ \\
ANN1 & $-17.85 \pm 0.01^{\mathrm{d}}$ & $-17.72 \pm 0.01^{\mathrm{d}}$ & $-18.39 \pm 0.03^{\mathrm{d}}$ & $0.54 \pm 0.04^{\mathrm{b}}$ & $-92.36 \pm 0.03^{\mathrm{a}}$ \\
ANN2 & $-13.80 \pm 0.02^{\mathrm{b}}$ & $-13.87 \pm 0.02^{\mathrm{b}}$ & $-14.40 \pm 0.01^{\mathrm{b}}$ & $0.60 \pm 0.03^{\mathrm{b}}$ & $-92.75 \pm 0.05^{\mathrm{a}}$ \\
ANN3 & $-16.97 \pm 0.01^{\mathrm{c}}$ & $-16.98 \pm 0.02^{\mathrm{c}}$ & $-17.55 \pm 0.01^{\mathrm{c}}$ & $0.58 \pm 0.02^{\mathrm{b}}$ & $-93.01^{\mathrm{b}} \pm 0.03^{\mathrm{a}}$ \\
\hline
\end{tabular}

Note: Abbreviations: ANN1, 55\% moisture, $50{ }^{\circ} \mathrm{C}, 4 \mathrm{~h}$; ANN2, 55\% moisture, $50{ }^{\circ} \mathrm{C}, 6 \mathrm{~h}$; ANN3, 50\% moisture $55^{\circ} \mathrm{C}, 6 \mathrm{~h} . \mathrm{T}_{\mathrm{fo}}$, the freezing onset temperature; $\mathrm{T}_{\mathrm{fp}}$, the freezing peak temperature; $\mathrm{T}_{\mathrm{fc}}$, the freezing conclusion temperature; $\mathrm{T}_{\mathrm{fc}}-\mathrm{T}_{\mathrm{fo}}$, the freezing temperature range; $\triangle \mathrm{H}_{\mathrm{f}}$, freezing enthalpy. Results are expressed as mean \pm standard deviation. The letters $\mathrm{a}, \mathrm{b}, \mathrm{c}$ and $\mathrm{d}$ indicated significant differences $(p<0.05)$ among the groups.

\subsection{Water Distribution in Dumplings Made from Glutinous Rice Flour}

LF-NMRis a rapid non-destructive detection technique used to analyze the distribution of water in food system [30,31]. The $T_{2}$ could be used to reflect the different degree in the water, because it was very sensitive to molecular mobility changes [30,32]. LF-NMR was used to determine the water distribution in fast-frozen dumplings made from the native and annealed glutinous rice flour, and the results are shown in Figure 5a. There were 3 peaks from left to right in each sample in $0.02-0.3 \mathrm{~ms}, 0.3-3 \mathrm{~ms}$ and $3-40 \mathrm{~ms}$, respectively, and the corresponding $\mathrm{T}_{2}$ was at $0.1 \mathrm{~ms}, 1 \mathrm{~ms}$ and $10 \mathrm{~ms}$, respectively. According to $\mathrm{T}_{2}$, the water is mainly divided into bound water of 0.01 to $10 \mathrm{~ms}$, immobilized water of 10 to $100 \mathrm{~ms}$, and free water of 100 to $1000 \mathrm{~ms}$ [33]. In Figure 5a, the first and second peak represented bound water while the third peak represented immobilized water. It indicated that the water in fast-frozen dumplings was mainly bound water and immobilized water, and the content of immobilized water was significantly higher than that of bound water. In general, the bound water is resulted from intra-granular water, immobilized water is resulted from the overlapping populations of starch extra-granular water and the water in the starch matrix [33]. For glutinous rice flour, the lower $\mathrm{T}_{2}$ indicated that the bound of water and starch was tight, and the mobility of water molecules was weakened, which lead to the restriction in swelling of starch granules [30].

Figure $5 b, c$ showed that the bound water increased, and the immobilized water decreased for fast-frozen dumplings made from annealed glutinous rice flour as compared with the control group, especially for ANN1 and ANN2. Compared with the dumplings made from annealed glutinous rice flour, the dumplings made from native glutinous rice flour had higher free water, and large ice crystals would be formed during freezing. Wang et al. [31] found that the more freedom water, the larger ice crystals that lead to the cracking. It was reported that the content of bound water increased and immobilized water decreased, which improved the quality of frozen dumplings [34].

\subsection{Paste Soup Ratio of Fast-Frozen Dumpling after Cooking}

The weak hydrogen bonds in the crystalline micellar area were destroyed by heating during cooking process. The starch granules were ruptured after hydration and swelling by water absorption, thus most of the amylose leached from the starch granule to the soup, that make the light transmittance decreasing. Paste soup ratio of different dumpling samples after cooking was shown in Figure 6. The light transmittance of the soup from the dumplings made of annealed rice flour increased, so the paste soup ratio was reduced, indicating the quality of fast-frozen dumplings was improved. The glutinous rice flour after annealing had less surface powder loss. During the freeze-thaw cycle, the dumplings had a good water-holding ability. The dumplings made from ANN2 sample showed the highest light transmittance. 

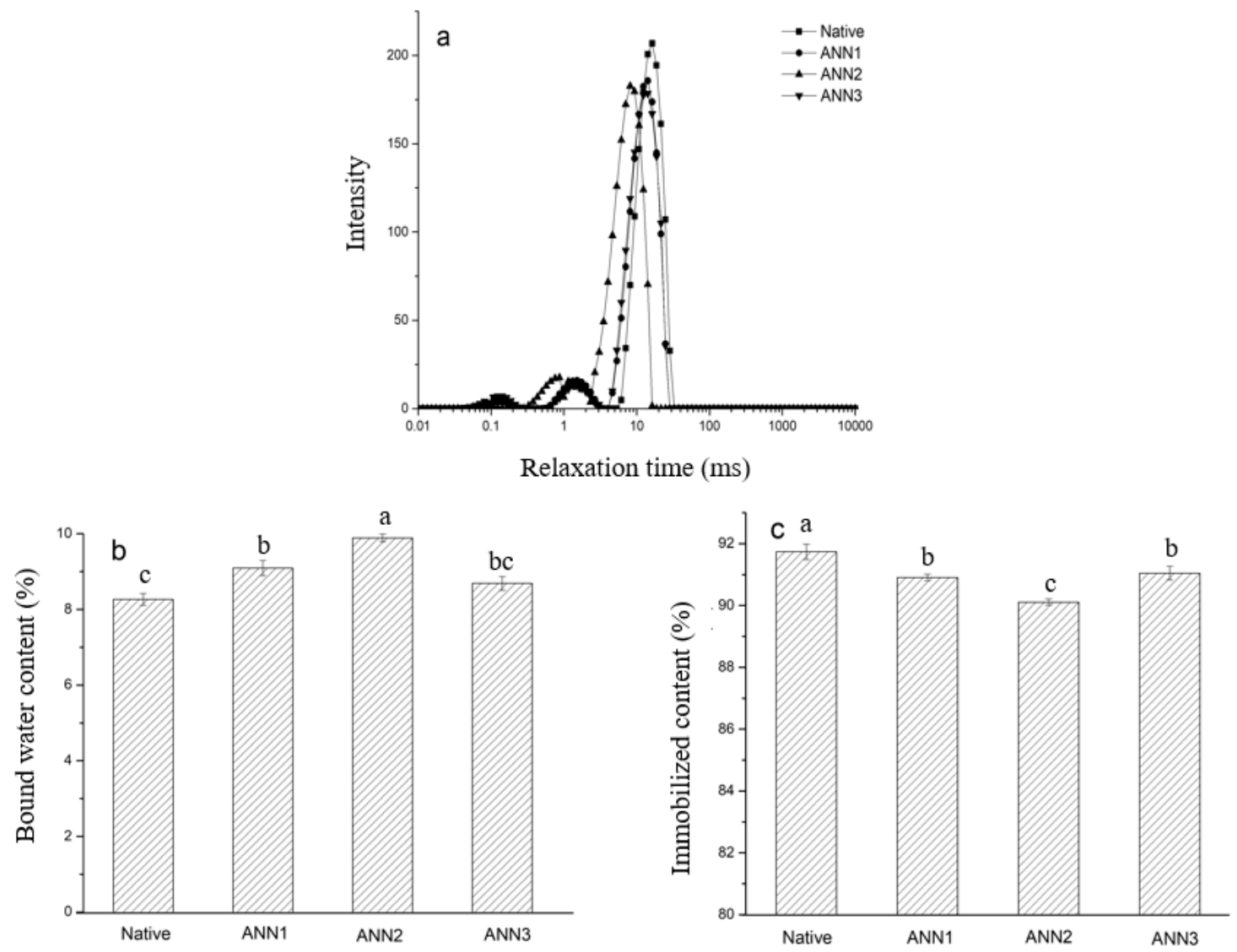

Figure 5. The distribution of water of fast-frozen glutinous dumplings made from native and annealed glutinous rice flour: (a) the curve of water distribution; (b) the content of bound water; (c) the content of immobilized water. ANN1, $55 \%$ moisture, $50{ }^{\circ} \mathrm{C}, 4 \mathrm{~h}$; ANN2, 55\% moisture, $50{ }^{\circ} \mathrm{C}, 6 \mathrm{~h}$; ANN3, 50\% moisture, $55^{\circ} \mathrm{C}, 6 \mathrm{~h}$. Results are expressed as mean \pm standard deviation. The letters $\mathrm{a}, \mathrm{b}$, and $\mathrm{c}$ above the bars indicated significant differences $(p<0.05)$ among the groups.

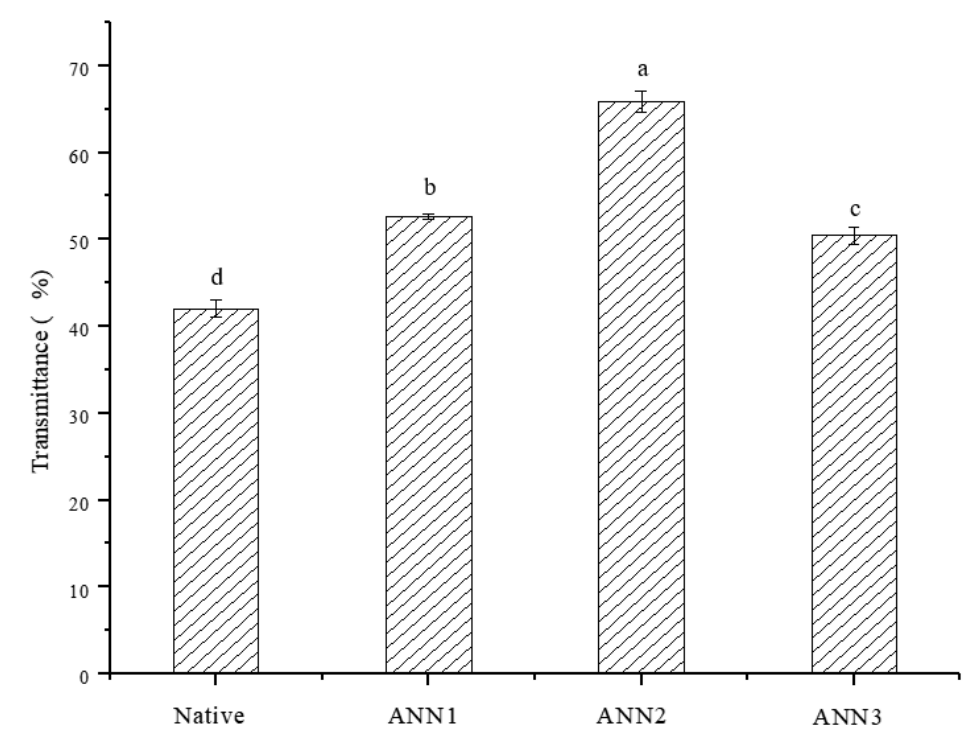

Figure 6. Transmittance of the soup of fast-frozen glutinous dumplings after boiling. Results are expressed as mean \pm standard deviation. The letters $a, b, c$ and $d$ above the bars indicated significant differences $(p<0.05)$ among the groups. 


\section{Conclusions}

The physicochemical and structure characteristics of the glutinous rice flour and its fast-frozen dumpling product were affected by annealing treatment. The crystallinity of annealed glutinous rice flour increased, and the structure was more orderly, which reduced the hydration ability of the flour. The thixotropic properties improved, indicating the improvement of flour network structure. The content of bound water increased, and immobilized water reduced for the annealed glutinous rice flour. The freezing point and enthalpy decreased, but the temperature range narrowed, which was facilitated to protect the structure and quality of product. The soup from boiled dumplings made of annealed flour showed high transmittance. Overall, annealed glutinous rice flour ANN2 had optimal physicochemical properties to make dumplings. It indicated that moderate annealing treatment of glutinous rice flour was conducive to produce high quality glutinous rice dumplings.

Author Contributions: Conceptualization, C.S. and Y.L.; methodology, C.S.; validation, C.S. and S.Z.; formal analysis, G.D. and C.D.; investigation, C.S. and G.D.; data curation, Y.L.; writing original draft paper, C.S.; writing-review and editing, Y.L. and D.H.; visualization S.Z. and Y.L.; funding acquisition, Y.L. and S.Z. All authors have read and agreed to the published version of the manuscript.

Funding: This research was funded by the National Science Foundation of China, Grant/Award Number: 31871794, 32172197; 111 project, Grant/Award Number: B0719028.

Institutional Review Board Statement: Not applicable.

Informed Consent Statement: Not applicable.

Data Availability Statement: Data generated or analyzed during this study are included in this published article.

Acknowledgments: The research was supported by the National Natural Science Foundation of China (No. 31871794, 32172197), 111 project (B0719028), national first-class discipline program of Food Science and Technology (JUFSTR20180204), and program of "Collaborative Innovation Center of Food Safety and Quality Control in Jiangsu Province", China.

Conflicts of Interest: There is no conflict of interest to declare.

\section{References}

1. Li, Z.; Wang, L.; Chen, Z.; Yu, Q.; Feng, W. Impact of protein content on processing and texture properties of waxy rice flour and glutinous dumpling. J. Cereal Sci. 2018, 81, 30-36. [CrossRef]

2. Lin, Z.; Geng, D.; Qin, W.; Huang, J.; Wang, L.; Liu, L.; Tong, L. Effects of damaged starch on glutinous rice flour properties and sweet dumpling qualities. Int. J. Biol. Macromol. 2021, 181, 390-397. [CrossRef]

3. Li, Y.; Ding, G.; Yokoyama, W.; Zhong, F. Characteristics of annealed glutinous rice flour and its formation of fast-frozen dumplings. J. Cereal Sci. 2018, 79, 106-112. [CrossRef]

4. Laokuldilok, T.; Surawang, S.; Klinhom, J. Effect of Milling on the Color, Nutritional Properties, and Antioxidant Contents of Glutinous Black Rice. Cereal Chem. 2013, 90, 552-557. [CrossRef]

5. Huang, Z.; Chen, J.; Song, H.; Huang, W.J.; Yang, Q.H.; Pan, Y.L.; Li, Z.; Ai, Z.L. Correlation analysis between characteristics of glutinous rice flour and quality of quick-frozen dumplings. Sci. Technol. Food Ind. 2019, 4, 93-99.

6. Zhou, X.Q.; Hu, Y.N.; Zhang, Y.R.; Deng, F.; Zhang, Z.C. Status and prospects of processing and quality control for the frozen rice dumplings in China. Sci. Technol. Cereals Oils Foods 2014, 2, 6-11.

7. Laura, M.F.; Shanise, L.M.; Alvaro, R.G.; Elessandra, R.Z. Physical modification of starch by heat-moisture treatment and annealing and their applications: A review. Carbohydr. Polym. 2021, 274, 118665.

8. Guo, B.; Wang, Y.; Pang, M.; Wu, J.; Liu, C. Annealing treatment of amylose and amylo pectin extracted from rice starch. Int. J. Biol. Macromol. 2020, 164, 3496-3500. [CrossRef]

9. Jayakody, L.; Hoover, R. Effect of annealing on the molecular structure and physicochemical properties of starches from different botanical origins-A review. Carbohydr. Polym. 2008, 74, 691-703. [CrossRef]

10. Tsutsui, K.; Katsuta, K.; Matoba, T.; Takemasa, M.; Funami, T.; Sato, E.; Nishinari, K. Effects of time and temperature of annealing on rheological and thermal properties of rice starch suspensions during gelatinization. J. Text. Stud. 2013, 44, 21-33. [CrossRef]

11. Wang, L.; Zhang, C.; Chen, Z.; Wang, X.; Wang, K.; Li, Y.; Wang, R.; Luo, X.; Li, Y.; Li, J. Effect of annealing on the physico-chemical properties of rice starch and the quality of rice noodles. J. Cereal Sci. 2018, 84, 125-131. [CrossRef] 
12. Ghani, M.B.A.; Man, Y.B.C.; Hashim, D.M.; Rahman, R.A. A differential scanning calorimetric (DSC) study on the effects of annealing and sugars-emulsifiers on gelatinization of sago starch (Metroxylon sagu). J. Food Process. Preserv. 2007, $23,443-462$. [CrossRef]

13. Chang, R.; Xiong, L.; Li, M.; Liu, J.; Wang, Y.; Chen, H.; Sun, Q. Fractionation of debranched starch with different molecular weights via edible alcohol precipitation. Food Hydrocoll. 2018, 83, 430-437. [CrossRef]

14. Abebe, W.; Collar, C.; Ronda, F. Impact of variety type and particle size distribution on starch enzymatic hydrolysis and functional properties of tef flours. Carbohydr. Polym. 2015, 115, 260-268. [CrossRef]

15. Tran, N.; Daygon, V.; Resurreccion, A.; Cuevas, R.; Corpuz, H.; Fitzgerald, M. A single nucleotide polymorphism in the Waxy gene explains a significant component of gel consistency. Theor. Appl. Genet. 2011, 123, 519-525. [CrossRef]

16. Yue, L.; Shoemaker, C.F.; Ma, J.; Luo, C.; Zhong, F. Effects of Alcalase/Protease N treatments on rice starch isolation and their effects on its properties. Food Chem. 2009, 114, 821-828.

17. Yokoyama, W.; Renner-Nantz, J.J.; Shoemaker, C.F. Starch Molecular Mass and Size by Size-Exclusion Chromatography in DMSO-LiBr Coupled with Multiple Angle Laser Light Scattering. Cereal Chem. 1998, 75, 530-535. [CrossRef]

18. Zeng, F.; Ma, F.; Kong, F.; Gao, Q.; Yu, S. Physicochemical properties and digestibility of hydrothermally treated waxy rice starch. Food Chem. 2015, 172, 92-98. [CrossRef]

19. Millard, M.M.; Dintzis, F.R.; Willett, J.; Klavons, J.A. Light-scattering molecular weights and intrinsic viscosities of processed waxy maize starches in 90\% dimethyl sulfoxide and $\mathrm{H}_{2}$ O. Cereal Chem. 1997, 74, 687-691. [CrossRef]

20. Wang, S.; Jin, F.; Yu, J. Pea starch annealing: New insights. Food Bioprocess Technol. 2013, 6, 3564-3575. [CrossRef]

21. Wang, S.; Wang, J.; Yu, J.; Wang, S. A comparative study of annealing of waxy, normal and high-amylose maize starches: The role of amylose molecules. Food Chem. 2014, 164, 332-338. [CrossRef]

22. Villanueva, M.; De Lamo, B.; Harasym, J.; Ronda, F. Microwave radiation and protein addition modulate hydration, pasting and gel rheological characteristics of rice and potato starches. Carbohydr. Polym. 2018, 201, 374-381. [CrossRef]

23. Chen, J.J.; Lu, S.; Lii, C.Y. Effects of Milling on the Physicochemical Characteristics of Waxy Rice in Taiwan. Cereal Chem. 1999, 76, 796-799. [CrossRef]

24. Iromidayoolu-Owolabi, B.; Adeniyiafolabi, T.; Adebowale, K. Pasting, Thermal, Hydration, and Functional Properties of Annealed and Heat-Moisture Treated Starch of Sword Bean (Canavalia gladiata). Int. J. Food Prop. 2011, 14, 157-174. [CrossRef]

25. Xu, M.; Saleh, A.S.M.; Gong, B.; Li, B.; Jing, L.; Gou, M.; Jiang, H.; Li, W. The effect of repeated versus continuous annealing on structural, physicochemical, and digestive properties of potato starch. Food Res. Int. 2018, 111, 324-333. [CrossRef]

26. Alimi, B.A.; Workneh, T.S.; Sibomana, M.S. Effect of hydrothermal modifications on functional, pasting and structural properties of false banana (Ensete ventricosum) starch. Food Biophys. 2016, 11, 248-256. [CrossRef]

27. Sikora, M.; Adamczyk, G.; Krystyjan, M.; Dobosz, A.; Tomasik, P.; Berski, W.; Lukasiewicz, M.; Izak, P. Thixotropic properties of normal potato starch depending on the degree of the granules pasting. Carbohydr. Polym. 2015, 121, 254-264. [CrossRef]

28. Wang, B.; Wang, L.J.; Li, D.; Özkan, N.; Li, S.J.; Mao, Z.H. Rheological properties of waxy maize starch and xanthan gum mixtures in the presence of sucrose. Carbohydr. Polym. 2009, 77, 472-481. [CrossRef]

29. Adamczyk, G.; Krystyjan, M.; Jaworska, G. The Effect of the Addition of Dietary Fibers from Apple and Oat on the Rheological and Textural Properties of Waxy Potato Starch. Polymers 2020, 12, 321. [CrossRef]

30. Ma, S.; Zhu, P.; Wang, M. Effects of konjac glucomannan on pasting and rheological properties of corn starch. Food Hydrocoll. 2019, 89, 234-240. [CrossRef]

31. Wang, S.; Lin, R.; Cheng, S.; Wang, Z.; Tan, M. Assessment of Water Mobility in Surf Clam and Soy Protein System during Gelation Using LF-NMR Technique. Foods 2020, 9, 213. [CrossRef]

32. Shao, J.H.; Deng, Y.M.; Jia, N.; Li, R.R.; Cao, J.X.; Liu, D.Y.; Li, J.R. Low-field NMR determination of water distribution in meat batters with $\mathrm{NaCl}$ and polyphosphate addition. Food Chem. 2016, 200, 308-314. [CrossRef]

33. Niu, M.; Xiong, L.; Zhang, B.; Jia, C.; Zhao, S. Comparative study on protein polymerization in whole-wheat dough modified by transglutaminase and glucose oxidase. LWT-Food Sci. Technol. 2018, 90, 323-330. [CrossRef]

34. Wang, H.; Xiao, N.; Wang, X.; Zhao, X.; Zhang, H. Effect of pregelatinized starch on the characteristics, microstructures, and quality attributes of glutinous rice flour and dumplings. Food Chem. 2019, 283, 248-256. [CrossRef] [PubMed] 